\title{
Development of new deactivation method for simulation of fluid catalytic cracking equilibrium catalyst
}

\author{
T CHIRANJEEVI*, D T GOKAK, V RAVIKUMAR and P S VISWANATHAN \\ Corporate R\&D Centre, Bharat Petroleum Corporation Ltd., Greater Noida 201 301, India \\ e-mail: chiranjeevit@bharatpetroleum.in; chiranjeevi13@yahoo.co.in
}

MS received 2 July 2013; revised 21 December 2013; accepted 23 December 2013

\begin{abstract}
Selection of a good catalyst is the easiest way to increase profitability of a fluid catalytic cracking (FCC) unit. During operation, these catalysts get deactivated due to operation at high temperatures, steam and deposition of metals on the catalyst. Developing a proper catalyst deactivation method is crucial for optimization of a good catalyst for FCC. Conventional laboratory deactivation procedures include direct metal impregnation method, cyclic deactivation method (CDM) and cyclic propylene steaming (CPS). Direct metal impregnation method gives higher coke and gas yields. CDM and CPS methods implementation is very difficult and time-consuming and there is a deviation in coke and gas yield. New rapid deactivation method has been developed to simulate plant equilibrium catalyst (E-Cat) by modifying metal impregnation, steaming and oxidation/reduction procedures. The E-Cat generated through a new deactivation method was characterized for physico-chemical properties using $X$ ray diffraction (XRD), temperature-programmed reduction (TPR), and SEM-EDX and activity studies. XRD studies show that metals are dispersed well on catalyst samples. SEMEDX studies reveal that the morphology of simulated E-Cat and plant E-Cat catalyst particles appear to be same. E-Cat obtained by new deactivation method gives better coke and gas yields. Two E-Cats were also generated through CDM and direct metal impregnation method for comparing with the one generated through new method. New deactivation method also significantly reduces the evaluation time.
\end{abstract}

Keywords. Fluid catalytic cracking (FCC); steam deactivation; metal deactivation; catalyst selection; FCC additives.

\section{Introduction}

Fluid catalytic cracking (FCC) is a major secondary processing unit in the petroleum industry for converting gas oil streams into high octane gasoline, cycle oils, and LPG and light olefins. Following the carbon rejection route, it upgrades low value streams such as vacuum gas oil, atmospheric residue, deasphalted heavy oils, etc., into distillates operating at low pressures and moderate temperatures. It is important in refineries owing to its feed flexibility, ability to produce diverse products and quick response to the market demands through minor changes in process operating conditions and catalyst. Economics of the FCC process are so attractive that it is almost impossible to imagine a modern refinery without this unit.

Selection of suitable catalyst for FCC unit through laboratory evaluation procedure helps selection of better catalyst and is one way of enhancing the FCC margin. ${ }^{1}$ Fresh FCC catalyst performance evaluation in the laboratory and predicting plant yields accurately is a challenging task. Performance evaluation is carried out

*For correspondence on lab-deactivated catalysts in Micro Activity Testing (MAT) unit. Since the lab-deactivated catalyst has to simulate the plant equilibrium catalyst, the methodology adopted for lab catalyst deactivation is crucial in the evaluation process. Generally, the lab deactivation process involves two steps; one is steam deactivation and the other is metal deactivation. Since zeolites have framework alumina, steaming causes deactivation. In FCC process, catalyst ages for almost 3 months before being withdrawn from the process which is generally referred to as equilibrium catalyst (E-Cat).

Mitchell ${ }^{2}$ tried to simulate E-Cat in the lab using fresh catalyst by direct metal impregnation of nickel and vanadium salts followed by steaming. Other methods followed are cyclic metal deactivation and cyclic propylene steaming. In cyclic metal deactivation, fresh catalyst is submitted to repeated cycles of cracking with metal-doped vacuum gas oil (VGO) followed by regeneration, reduction and steaming. ${ }^{3-5}$ In cyclic propylene steaming (CPS) ${ }^{6,7}$ after direct deposition of metals, the catalyst is submitted to reduction-oxidation cycles using propylene as the reducing agent followed by steaming. Comparison of cyclic deactivation method (CDM) and Mitchell method at same activity by 


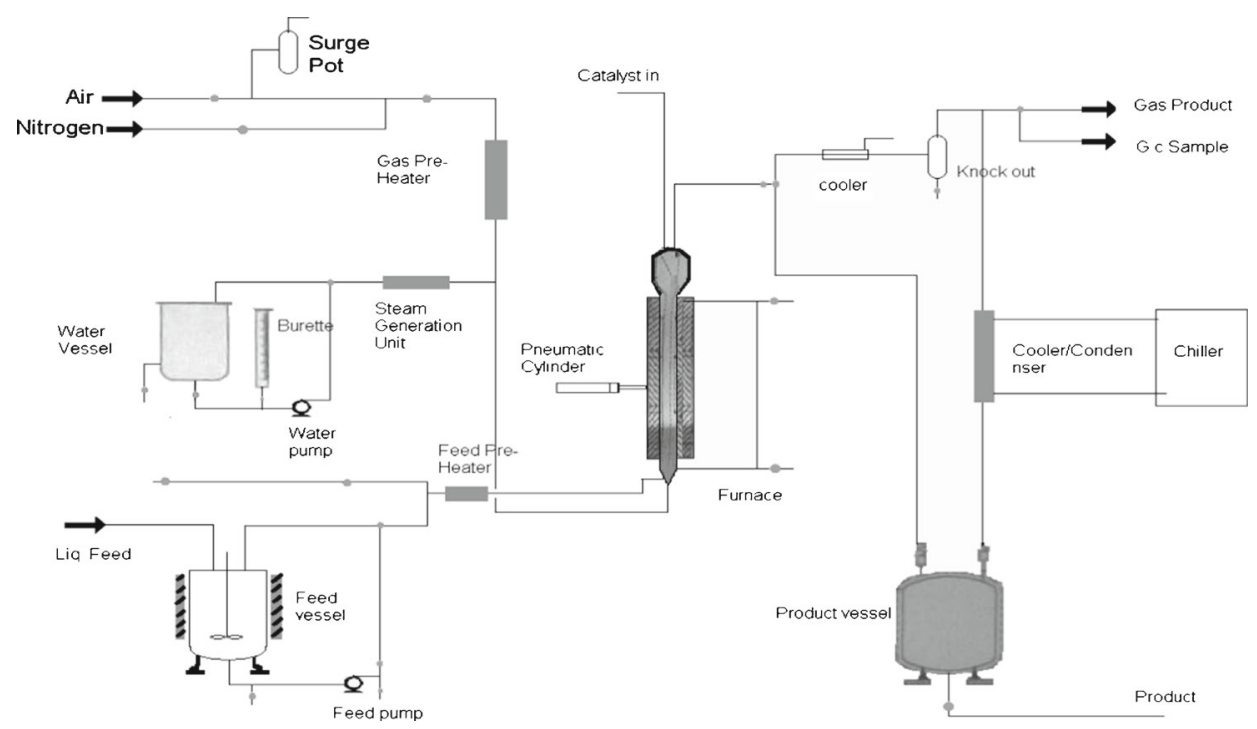

Figure 1. Steam deactivation unit.

previously adjusting the metals and deactivation conditions reveals that cyclic deactivation is better than other methods. ${ }^{8}$

Different deactivation methods are practised worldwide; however there is general consensus on lab equilibrium catalyst generated through CDM which is similar to the plant equilibrium catalyst. ${ }^{9-14}$ However this method is more cumbersome, time-consuming, costintensive and more variations in coke and gas make are observed. Mitchell catalyst deactivation was also not accepted well because it yields more gas and coke. Formation of more gas and coke in case of direct metal impregnation method was studied by using SEM, EDX and temperature-programmed reduction (TPR) techniques. $^{15}$

The present communication deals with development of new deactivation method which is faster and simulates plant equilibrium catalyst better in the lab. Different lab-deactivated catalysts are prepared and results are explained in the light of characterization and evaluation studies.

\section{Experimental}

\subsection{Laboratory deactivation}

Both fresh and E-Cat samples were obtained from a commercial FCC unit.

2.1a New deactivation method: Metal deactivation was carried out using octovate salts of nickel and vanadium containing $4 \%$ and $8 \%$ solution. Prior to metaldeposition, fresh catalyst was calcined at $650^{\circ} \mathrm{C}$ for $1 \mathrm{~h}$ in air. Different weight percentages of metal loading were carried out at room temperature by pore-filling technique. Metal-loaded samples were dried at $110^{\circ} \mathrm{C}$ for $12 \mathrm{~h}$ and calcined at $550^{\circ} \mathrm{C}$ for $4 \mathrm{~h}$. The above samples were subjected to oxidation in presence of air and reduction in presence of $\mathrm{H}_{2}-\mathrm{N}_{2}$ mixture $\left(5 \% \mathrm{H}_{2}\right.$ in $\mathrm{N}_{2}$ and steaming in a fixed fluid bed reactor (figure 1) sequentially. Steam deactivation was carried out at two temperatures to optimize catalyst deactivation. Deactivation conditions adopted for generating different lab equilibrium catalyst are presented in table 1 .

2.1b Cyclic deactivation method: Cyclic deactivation studies were carried out by the following method described in literature. ${ }^{8}$ Experimental set-up used for the study is shown in figure 1. Plant equilibrium catalyst equivalent to amount of nickel and vanadium metals were loaded on fresh catalyst in cycles through metaldoped VGO cracking, regeneration and steaming steps. More details of deactivation are given in table 2.

2.1c Direct metal deactivation method: Direct metal deactivation studies were carried out by following Mitchell method where metals equal to plant equilibrium catalyst were directly impregnated on fresh catalyst and subsequently steamed. ${ }^{2}$

\subsection{Characterization studies}

2.2a $X$-ray diffraction: $\quad$ Unit cell parameter (UCS) of the lab-deactivated catalysts was determined by X-ray powder diffraction (using a Philips X'pert Pro) as per ASTM D 3942-97. X-ray spectra was recorded with Cu 
Table 1. Catalysts deactivated under different conditions.

\begin{tabular}{llccc}
\hline Catalyst & $\begin{array}{l}\text { Metal loading } \\
(\% \text { of E-Cat) }\end{array}$ & $\begin{array}{l}\text { Oxidation in air } \\
\text { at } 680^{\circ} \mathrm{C} \text { for } 3 \mathrm{~h}\end{array}$ & $\begin{array}{l}\text { Reduction } 5 \% \mathrm{H}_{2} \\
\text { in } \mathrm{N}_{2} \text { at } 550^{\circ} \mathrm{C} \text { for } 3 \mathrm{~h}\end{array}$ & Steaming \\
\hline CAT 1 & $100 \% \mathrm{Ni}$ and V & Yes & Yes & $760^{\circ} \mathrm{C} 13 \mathrm{~h}$ \\
CAT 2 & $50 \% \mathrm{Ni}$ and V & Yes & Yes & $760^{\circ} \mathrm{C} 13 \mathrm{~h}$ \\
CAT 3 & $33 \% \mathrm{Ni}$ and V & Yes & Yes & $816^{\circ} \mathrm{C} 13 \mathrm{~h}$ \\
CAT 4 & $25 \% \mathrm{Ni}$ and V & Yes & Yes & $816^{\circ} \mathrm{C} 13 \mathrm{~h}$ \\
\hline
\end{tabular}

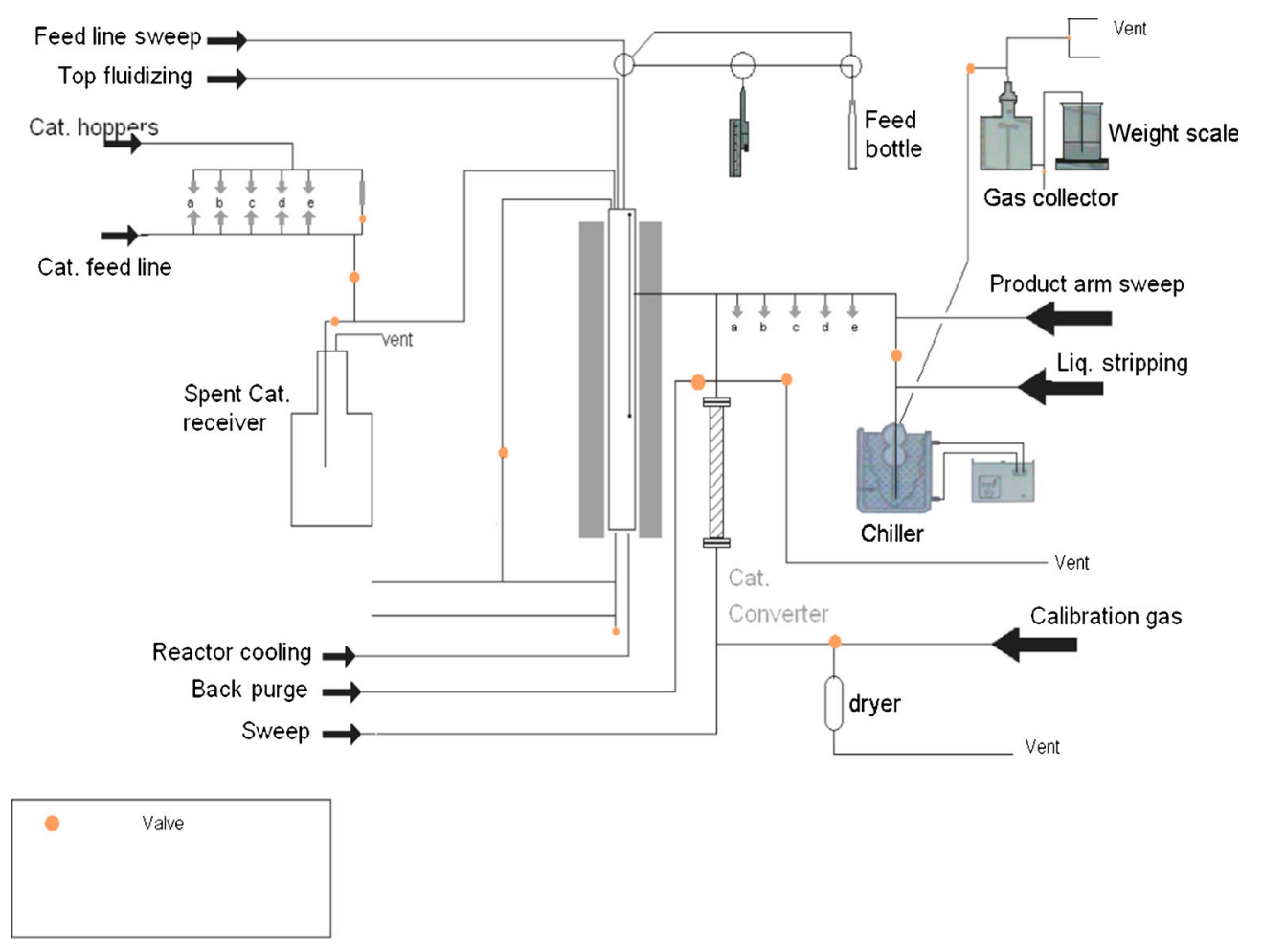

Figure 2. Micro activity testing unit.

$\mathrm{K}$ alpha radiation $\left(1.540560 \AA\right.$ ) with a $0.02^{\circ}$ step size and over the range of $2^{\circ}<2 \theta<40^{\circ}$.

2.2b Textural properties: Textural properties of catalyst samples were determined by using nitrogen adsorption/desorption isotherms measured by Autosorb-1MP (Quanta chrome, USA) unit. Nitrogen adsorption/desorption isotherms were measured at $-196^{\circ} \mathrm{C}$ after degassing about $100 \mathrm{mg}$ of sample below $10^{-3}$ torr at $350^{\circ} \mathrm{C}$ for $3 \mathrm{~h}$. The BET-specific surface area was estimated by following ASTM method (366399) using adsorption data in a relative pressure range of 0.008 to 0.08 . Matrix surface area of the catalysts was determined by T-plot method.

2.2c Temperature programmed reduction: TPR study was carried out by using Altamira (AMI 200)
Table 2. Conditions for cyclic metal deactivation (CD) method.

\begin{tabular}{|c|c|}
\hline Parameter & Quantity \\
\hline Catalyst quantity & $100 \mathrm{~g}$ \\
\hline Catalyst bed temperature & $\begin{array}{l}515^{\circ} \mathrm{C} \text { during reaction } \\
675^{\circ} \mathrm{C} \text { during regeneration }\end{array}$ \\
\hline $\begin{array}{l}\text { Targeted nickel } \\
\text { concentration }\end{array}$ & $4460 \mathrm{ppm}$ \\
\hline $\begin{array}{l}\text { Targeted vanadium } \\
\text { concentration }\end{array}$ & $1310 \mathrm{ppm}$ \\
\hline Number of cycles & 20 \\
\hline VGO injection rate & $2.25 \mathrm{~g} / \mathrm{min}$ \\
\hline Injection time & $\approx 472 \mathrm{~s}$ \\
\hline Cycle time & $\approx 2 \mathrm{~h}$ \\
\hline $\begin{array}{l}\text { Reduction using } \\
5 \% \mathrm{H}_{2} \text { in nitrogen }\end{array}$ & $\begin{array}{l}\left(300^{\circ} \mathrm{C}, 400^{\circ} \mathrm{C}, 500^{\circ} \mathrm{C}, 600^{\circ} \mathrm{C},\right. \\
\left.700^{\circ} \mathrm{C}, 775^{\circ} \mathrm{C}\right) \text { Hold time at } \\
\text { each temperature for } 1 \mathrm{~h}\end{array}$ \\
\hline Steaming & $\begin{array}{l}\text { At } 816^{\circ} \mathrm{C} \text { for } 13 \mathrm{~h} \\
80 \% \text { steam }+ \text { nitrogen }\end{array}$ \\
\hline
\end{tabular}


Table 3. Physico-chemical properties of various deactivated catalysts.

\begin{tabular}{lcccccc}
\hline Catalyst & $\begin{array}{l}\text { Total S.A. } \\
\left(\mathrm{m}^{2} / \mathrm{g}\right)\end{array}$ & $\mathrm{Z} / \mathrm{M}$ & $\begin{array}{l}\text { Micro pore } \\
\text { area }\left(\mathrm{m}^{2} / \mathrm{g}\right)\end{array}$ & $\begin{array}{l}\text { Matrix surface } \\
\text { area }\left(\mathrm{m}^{2} / \mathrm{g}\right)\end{array}$ & Unit cell size $(\AA)$ & TPR data $\left(\mathrm{T}\right.$ max, $\left.{ }^{\circ} \mathrm{C}\right)$ \\
\hline CAT 1(100)* & 290 & 2.8 & 215 & 75 & 24.35 & 822 \\
CAT 2(50) & 210 & 3.3 & 162 & 48 & 24.35 & 842 \\
CAT 3(33) & 172 & 2.7 & 125 & 46 & 24.28 & 510 and 842 \\
CAT 4(25) & 185 & 2.1 & 126 & 59 & 24.25 & 538 and 839 \\
CD SD & 200 & 2.4 & 142 & 58 & 24.28 & 531 and 837 \\
MM & 280 & 2.73 & 205 & 75 & 24.35 & 821 \\
E-Cat & 171 & 4.0 & 137 & 34 & 24.28 & 534 and 840 \\
Fresh & 364 & 4.0 & 292 & 72 & 24.66 & - \\
\hline
\end{tabular}

where $\mathrm{Z} / \mathrm{M}=$ ratio of zeolite to matrix

$\mathrm{MM}=$ Mitchell method equilibrium catalyst

*Numbers in the bracket indicate percent E-Cat metals

TPR unit. In an experiment, $250 \mathrm{mg}$ of the catalyst sample was degassed in the flow of Argon at $300^{\circ} \mathrm{C}$ for $2 \mathrm{~h}$. Reduction was carried out using $5 \% \mathrm{H}_{2}$ in Argon at a flow rate of $35 \mathrm{ml} / \mathrm{min}$. Reduction temperature was ramped from $80^{\circ} \mathrm{C}$ to $1000^{\circ} \mathrm{C}$ at $10^{\circ} \mathrm{C} / \mathrm{min}$. Detector output is recorded as a function of temperature. Temperature at which maximum output occurs represents the reduction of a particular metal.

2.2d Scanning electron microscopy and energy dispersive $X$-rays: Morphological characteristics of the catalyst samples were examined by scanning electron microscopy (SEM, TESCAN, Vega-LSU) equipped with $\mathrm{X}$-ray microanalysis (OXFORD INCA PentaFET $\times 3$ ). Scanning electron microscope images were acquired at a magnification of $2.3 \mathrm{KX}$ at $2.00 \mathrm{KV}$ with SE detector. Surface metal profiling was achieved using the X-ray energy dispersive spectroscopy (EDS) system at a WD of 23.00 and $15 \mathrm{KV}$. Point analysis was done to ascertain the distribution of nickel and vanadium.

Powdered samples were dispersed on carbon-glued studs. Particles were analysed for morphology and metal profiling studies.

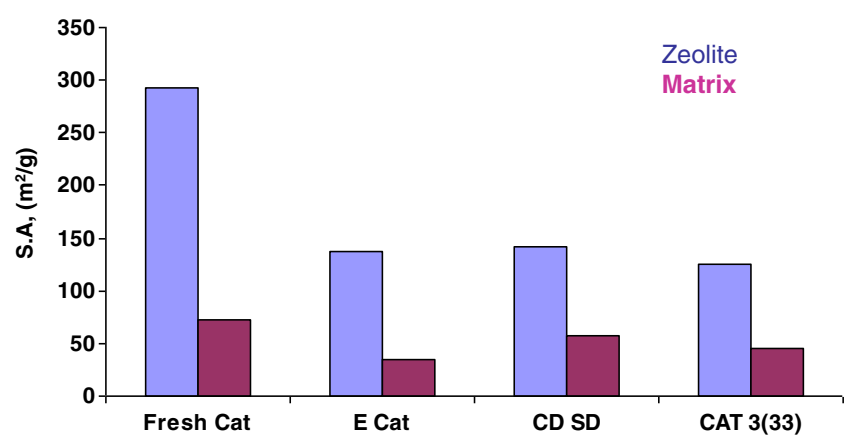

Figure 3. Textural properties of plant E-Cat, CDSD, new deactivation method E-Cat and FCC fresh catalyst.

\subsection{Activity studies}

Activity studies were carried out in a fixed fluid bed PC PLC-controlled bench scale unit (ACE-R+) supplied by M/s Xytel Corporation, USA and licensed by M/s Kayser Technologies, USA. The unit flow diagram is shown in figure 2. In a typical run, $9 \mathrm{~g}$ of catalyst was used for cracking of vacuum gas oil at catalyst to oil (Cat/Oil) ratio of 6.5 at $520^{\circ} \mathrm{C}$ using $\mathrm{N}_{2}$ as fluidizing media. The cracked gaseous products were condensed at $-12^{\circ} \mathrm{C}$ and stored. Gaseous products were analysed online using GC and liquid samples were analysed offline using Sim Dist GC. Coke generated during reaction were analysed by burning in air in the same reactor and using online IR analyser. Based on this analysis, activity and selectivity of the catalyst is calculated.

\section{Results and discussion}

From the textural properties of fresh and equilibrium catalyst (table 3), it is clear that the properties of fresh catalyst differ significantly from equilibrium catalyst in

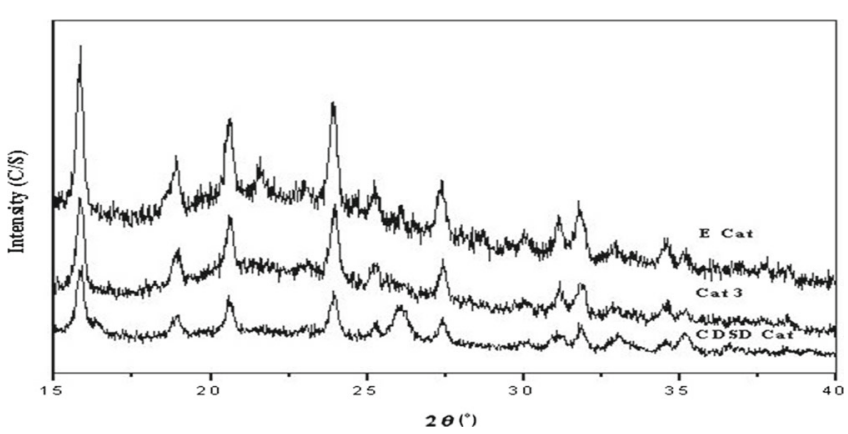

Figure 4. XRD spectra of E-Cat, 'CAT 3(33)' and CDSD catalysts. 


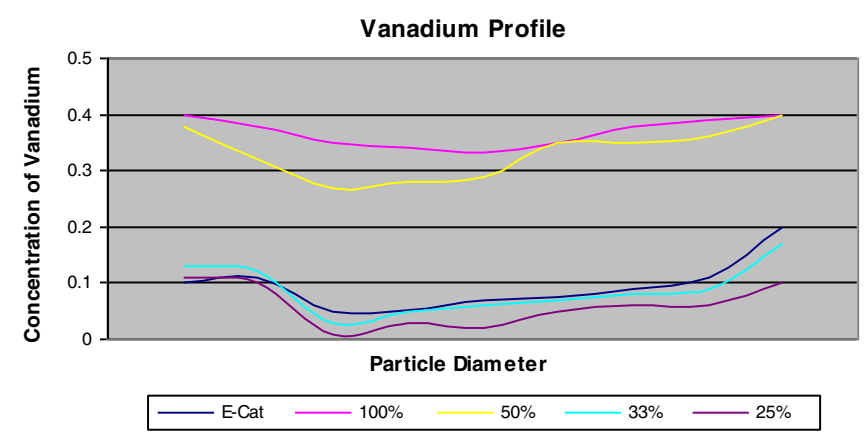

Figure 5. Vanadium metal distribution in catalyst particles.

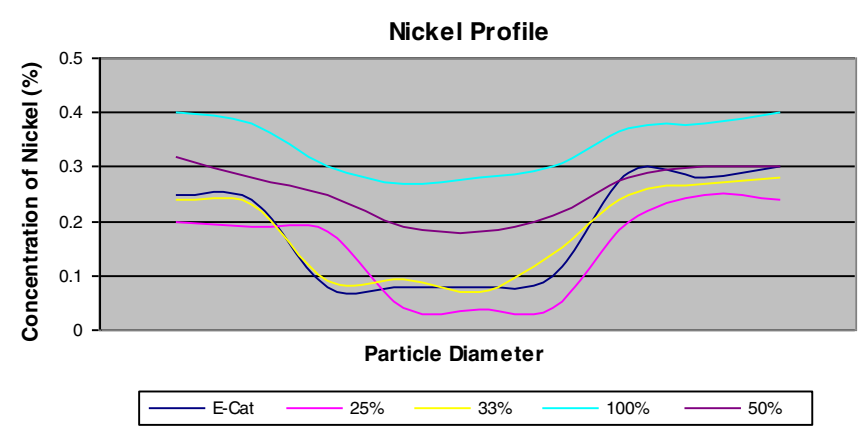

Figure 6. Nickel metal distribution in catalyst particles.

surface area, micro pore area, matrix surface area, unit cell parameters and metal content. In order to simulate plant equilibrium catalyst in laboratory, fresh catalyst properties, viz., total surface area, micro pore area, unit cell size to be reduced to the level of equilibrium catalyst and metals, have to be deposited to match equilibrium catalyst metal distribution.
Literature report suggest impregnation of exact metal quantity as in plant equilibrium catalyst (2). In the present method, concentration of metal is varied in the range of $25 \%$ to $100 \%$ of plant equilibrium catalyst metals (Ni: 4460, V: 1310) and followed by oxidation-reduction cycle and steaming (tables 1 and 2). Table 3 presents the physico-chemical characterization data of fresh catalyst, plant equilibrium catalyst and equilibrium catalysts generated by CDM and Mitchell method. Cyclic deactivated catalyst as well as CAT 3(33) exhibits lower zeolite to matrix (Z/M) ratios when compared to equilibrium catalyst. Difference in zeolite to matrix (Z/M ratios) indicates that different deactivation protocols are responsible for difference in obtaining the final catalyst. Even though total surface area of Cat 3(33) matches with plant E Cat it differs with zeolite to matrix $(\mathrm{Z} / \mathrm{M})$ ratio. Another interesting feature is that zeolite to matrix $(\mathrm{Z} / \mathrm{M})$ ratios of $\mathrm{CDM}$ and Mitchell method catalysts do not differ so much. Bendiksen et al. also reported similar observations (figure 3 ). ${ }^{8}$

Unit cell size (UCS) is another important parameter that provides information on the deactivation of zeolite. XRD spectra are presented in figure 4. UCS measured for different catalysts are listed in table 3 . Fresh catalyst UCS was reduced from 24.66 to 24.28 in case of equilibrium catalyst; similarly in case of CDM and Mitchell method and CAT 3(33). Higher UCS of other catalysts (CAT 1 (100) and CAT 2(50), MM) indicates that they are not sufficiently deactivated. Activity results also support UCS data. From tables 1 and 5 it is clear that equivalent amount of metal loading will not simulate plant equilibrium catalyst. However, by varying amount of metal loading and steaming conditions, plant

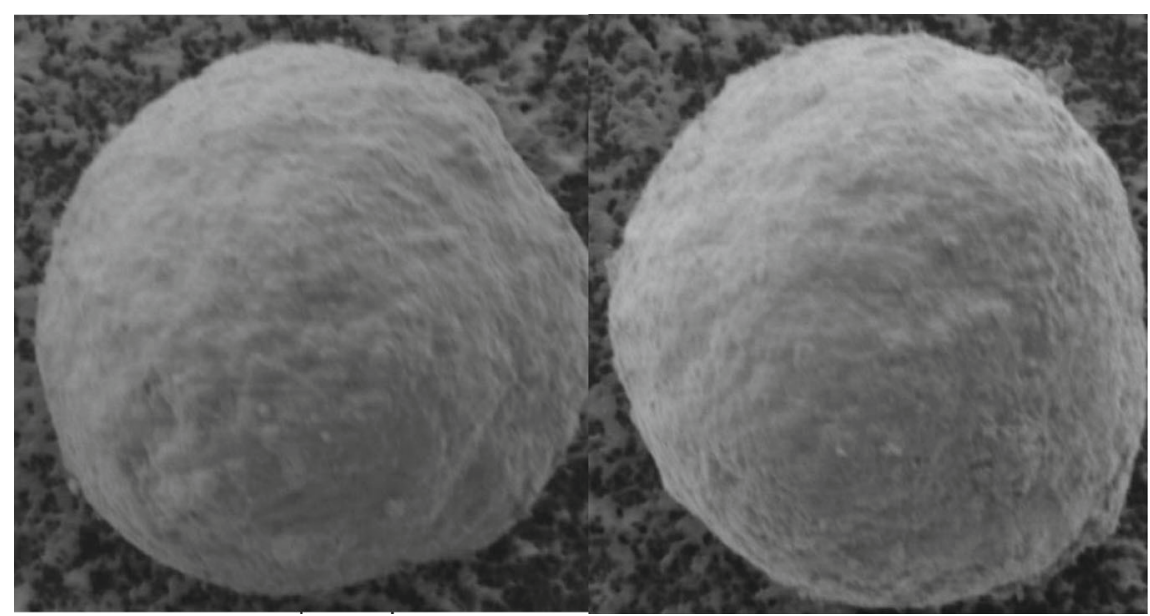

E- Cat

CAT 3(33)

Figure 7. SEM images of E-Cat and lab-deactivated catalyst (CAT 3(33)). 
Table 4. Bench-scale reaction conditions.

\begin{tabular}{ll}
\hline Parameter & Value \\
\hline Catalyst quantity $(\mathrm{g})$ & 6.5 \\
Oil injection rate $(\mathrm{g} / \mathrm{m})$ & 2.25 and 1.75 \\
Catalyst/oil ratio & 6.5 \\
Catalyst bed temperature $\left({ }^{\circ} \mathrm{C}\right)$ & 520 \\
Fluidization gas & Nitrogen \\
Regeneration temperature $\left({ }^{\circ} \mathrm{C}\right)$ & 695 \\
\hline
\end{tabular}

equilibrium catalyst was simulated (CAT 3(33) and CAT 4(25)).

TPR studies are useful in predicting reduction behaviour of metals in the reactor. TPR results of plant equilibrium catalysts presented in table 3 show two reduction peaks, first peak occurring at $534^{\circ} \mathrm{C}$ and the second peak at $840^{\circ} \mathrm{C}$. Reduction peak at $534^{\circ} \mathrm{C}$ corresponds to supported $\mathrm{V}_{2} \mathrm{O}_{5}$ and second peak appearing at $\sim 840^{\circ} \mathrm{C}$ is due to nickel silicate or nickel aluminates. Bayraktar et al. ${ }^{14}$ also observed similar type of reduction peaks for fluid catalytic cracking catalysts (14). CD, CAT 3(33) and CAT 4(25) also exhibited two reduction peaks similar to plant equilibrium catalyst. From these results it can be inferred that $\mathrm{Ni}$ and $\mathrm{V}$ reducible metal species present in CD, CAT 3(33) and CAT 4(25) samples are similar to those of equilibrium catalyst.

\subsection{SEM and EDX studies}

All the catalyst samples were scanned for SEM and EDX and the results reported are the average value of at least 10 readings. The purpose of this study was to investigate vanadium and nickel metal distribution on E-Cat and lab-simulated catalysts to match with commercially deactivated plant equilibrium catalyst. Point analysis study was carried out to investigate the internal locations of nickel or vanadium on catalyst particles. Various points were selected as a function of distance from the particle edge, or in areas of apparently different composition. Vanadium and nickel metal concentration profiles of equilibrium catalyst and labdeactivated samples CAT 1 (100) CAT 2(50), CAT
3(33), and CAT 4(25) were analysed and are shown in the figures 5 and 6 . Plant equilibrium catalyst profile shows that more metal is distributed in the edge rather than in the centre. Similar results were reported by Psarras et al. in their research communication. ${ }^{15}$ It was also reported that metal enrichment at different locations was attributed to aluminum enrichment which is quite possible during metal ageing. Concentrations of metals are uniform throughout the particle for labgenerated equilibrium catalyst samples (CAT 1 (100) and CAT 2(50)) by new deactivation method. Metal profile of CAT 3(33) and CAT 4(25), where the concentrations of metals are $33 \%$ and $25 \%$ of equilibrium catalyst metals, has more edge concentration than the bulk. Figure 7 presents morphological similarities of plant equilibrium catalyst and lab-simulated equilibrium catalyst (CAT 3(33)).

\subsection{Activity results}

MAT reaction conditions are shown in table 4. In terms of coke selectivity, dry gas and conversions, it is obvious that CAT 1 (100), CAT 2(50) and Mitchell method do not simulate the equilibrium catalyst performance (table 5). Characterization data also support the same conclusion. Coke selectivity for the catalyst prepared by the cyclic deactivation route and CAT 3(33) and CAT 4(25) are comparable. The catalyst sample generated by cyclic deactivation route provided a close match with equilibrium catalyst on conversion closely followed by CAT 3(33) and CAT 4(25) generated by new deactivation method.

From table 4, it is clear that the sum of LPG and gasoline yields closely match with equilibrium catalyst. However, with lab-deactivated catalysts prepared by following either the new deactivation method or the cyclic deactivation route, individual yields of LPG and gasoline differ with the equilibrium catalyst. Differences found are mainly due to plant E-Cat sample having particles of different ages and also containing additives used in the unit from time to time. In order to better simulate this heterogeneity and to match the individual yields of LPG and gasoline more closely, age

Table 5. Activity data of CAT 1 (100), CAT 2(50), MM and equilibrium catalysts.

\begin{tabular}{lccc}
\hline Catalyst & Conversion $(\%)$ & Coke yield $(w t \%)$ & Dry gas yield (wt\%) \\
\hline CAT1(100) & 79.4 & 10.3 & 2.7 \\
CAT 2(50) & 77.3 & 8.7 & 2.4 \\
MM & 78.1 & 9.1 & 2.8 \\
E-Cat & 67.6 & 5.1 & 1.5 \\
\hline
\end{tabular}


Table 6. Comparison of activity of catalysts deactivated by different methods.

\begin{tabular}{lcccc}
\hline & \multicolumn{2}{l}{ New deactivation method } & & CD SD method \\
\cline { 2 - 3 } & Cat-4(25) & Cat -3(33) & & Plant E-Cat \\
\hline Conv. (wt \%) & 68.1 & 68.7 & 67.4 & 67.6 \\
Coke (wt\%) & 5.7 & 5.7 & 5.7 & 5.1 \\
DG (wt\%) & 1.7 & 1.7 & 1.7 & 1.5 \\
LPG (wt\%) & 20.6 & 19.8 & 18.4 & 16.7 \\
Gasoline (wt\%) & 40.1 & 41.5 & 41.6 & 44.3 \\
LCO (wt\%) & 20.7 & 19.6 & 20.6 & 20.4 \\
HCO (wt\%) & 2.7 & 2.8 & 2.8 & 9.1 \\
CLO/bottom & 8.5 & 8.9 & 9.2 & 2.4 \\
Coke factor & 2.7 & 2.6 & 2.8 & 2.4 \\
\hline
\end{tabular}

where $\mathrm{CDSD}=$ cyclic deactivation along with steam deactivation

Table 7. Correlation of lab data with commercial plant data.

\begin{tabular}{lccc}
\hline & Lab prediction & Commercial plant yields & Deviation \\
\hline Conv. (wt\%) & 68.1 & 67.2 & -0.9 \\
Coke (wt\%) & 3.4 & 2.8 & -0.6 \\
DG (wt\%) & 1.7 & 1.4 & -0.3 \\
LPG (wt\%) & 17 & 16 & -1 \\
Gasoline (wt\%) & 46 & 47 & +1 \\
\hline
\end{tabular}

distribution effects may have to be incorporated in the deactivation protocol.

\subsection{Correlation of lab data with commercial data}

As part of selection of optimum catalyst for one of the commercial FCC plant, four vendor catalysts were deactivated by optimized new deactivation method and one catalyst was recommended for use. The recommended catalyst has been in use since the last 2 years. For the benefit of the reader, lab activity data is compared with commercial plant activity data (table 6).

From table 7, it is clear that lab-simulated equilibrium catalyst yield prediction matches with plant yield pattern with slight differences. Differences in yield pattern are mainly attributed to the variations in feed used in the plant and catalyst additives used in the course of operation.

\section{Conclusion}

A novel deactivation method was standardized to simulate FCC plant equilibrium catalyst properties and performance. The new deactivation method for simulating equilibrium catalyst in lab is cost-effective and saves time without compromising on plant yields. This deactivation protocol is extremely useful to refiners in selecting the best catalyst among many catalysts available in the market.

\section{Acknowledgements}

Authors thank Mr. N Ravichander for his contribution towards activity data and also thank the management of BPCL for permission to publish this data.

\section{References}

1. Ravichander N, Chiranjeevi T, Gokak D T, Ravi Kumar V and Choudary N V 2009 Catal. Today 141(1-2) 115

2. Mitchell B R 1980 Ind. Eng. Chem. Prod. Res. Dev. 19 209

3. Gerritsen L A, Winjngaards $\mathrm{H} \mathrm{N} \mathrm{J}$, Verwoert $\mathrm{J}$ and Connor P O 1994 Catal. Today 1161

4. Magee J S and Mitchell Jr M M 1993 Stud. Surf. Sci. Catal. 76223

5. Alyne S E, Marcelo M P, Ricardo D M Pimenta, Lam Y Lau and Heriqque S C 2005 Appl. Catal. A 286196

6. Wallenstein D, Kanz B and Harding R H 1999 Appl. Catal. 178117

7. Wallenstein D, Harding R H, Wizler J and Zhao X 1988 Appl. Catal. 167141

8. Bendiksen M, Tangstad E and Myrstad T 1995 Appl. Catal. 12921

9. Karthikeyani A V, Mandal S, Das A K, Krishnan V and Makhija S 2008 Proc. Intercat Seminar, Mumbai, 21 February, p.38 
10. Grace W R 1999 Grace Division Guide to FCC, part 3, Chapter 11

11. Biswas J and Maxwell I E 1990 Appl. Catal. 63197

12. Rainer D R and Rautiainen E P 2003 Appl. Catal. A 249 69
13. Speronello B K and Reagan W J 1984 Oil Gas J. 30139

14. Bayraktar O and Kugler E 2004 Appl. Catal. 260 125

15. Psarras A C, IIiopoulou E F, Nalbandian L, Lappas A A and Pouwels C 2007 Catal. Today 12744 